\title{
Green belt's effect on fine particle matter (PM2.5) in residential cluster: based on CFD simulation
}

\author{
Xiong changwei ${ }^{1}$, Chen qingchang ${ }^{1, *}$ \\ ${ }^{1}$ School of Urban Construction and Safety Engineering, Shanghai Institute of Technology, 201418 Shanghai Haiquan Road No.100, \\ China
}

\begin{abstract}
In the area of residential green belt planning, most planners pay attention to the landscape function of green belts, while few researchers consider the impact of green belt on the concentration of fine particulate matter in the air. Based on site investigation, information about plants, buildings and weather in the selected area were collected, combined with air pollution measurement, four CFD models with different green belt composition were built and simulated. The results showed that at the residential cluster scale, green belts had two effects on fine particles: blocking and agglomeration. Under the two effects, the role of green belts in reducing fine particulate pollution was not always positive, improper green belts could even aggravate air pollution. This study discussed the impact of different greenbelt composition on PM2.5 concentration in residential clusters by CFD simulation, providing theoretical and methodological support for green belt planning and healthy city planning.
\end{abstract}

\section{Introduction}

In recent years, the concentration of particulate matter with aerodynamic equivalent diameters of less than 2.5 microns (PM2.5) caused by industrial development has become higher and higher in urban areas, posing problem to urban residents' health ${ }^{[1]}$. In 2016, the State Council of China promulgated the "healthy 2030" planning outline, which clearly declared health problem had become one of the most important problems affect social development ${ }^{[2]}$. In this context, urban green space, which can eliminate air pollution and maintain residents' health, has attracted more attention of planners. Previous studies have shown that plants can reduce the concentration of PM2.5 in the air, and use urban green space to reduce air pollution is very economical. Nowak et al. ${ }^{[3]}$ find that shrubs and trees in the city can remove $7.11 * 10^{5}$ tons of air pollutants each year in US, creating about $\$ 38$ billion economic value.

However, most planners focus on landscape design and functional renovation of large and centralized urban park green space, few pay attention to small and scattered residential green belt. Mcdonald et al., ${ }^{[4]}$ and Dai Fei et al., ${ }^{[5]}$ find a negative correlation between green space area and air pollutant concentration at the urban scale, but this does not mean that their research results are still valid at the street or cluster scale. In order to provide reference and guidance for residential green belt planning, more research based on residential cluster should be conducted.

Although the scale of residential green belt is very small, it has confirmed impact on street's PM2.5 distribution. Guo xiaohua et al., ${ }^{[6]}$ study the effect of different green belts on PM2.5 concentrations in street by using Computational Fluid Dynamics (CFD) simulation software. They find green belts can significantly reduce the concentration of PM 2.5 in street sidewalks by blocking PM2.5 on motorway. Li xiangrong ${ }^{[7]}$ finds green belts composed of different plants have different resistance to PM2.5. Besides, he also points out green belts with shrubs reduce the accumulation of PM2.5 in front of buildings, which could be beneficial to optimize indoor air quality of buildings in residential area.

Since green belt can affects the distribution of PM2.5 in street canyons, exploring green belt's effect on fine particle concentration in residential area will make sense. In order to achieve this goal, one control group and three experimental groups with different kinds of green blet will be set. Based on field measurement equipment and CFD simulation software ENVI-met, the effect of green belts on the concentration and distribution of PM2.5 in residential clusters will be explored.

\section{Research objects and methods}

\subsection{Overview of the study area and subjects}

Shanghai $\left(120^{\circ} 52 \mathrm{E}-122^{\circ} 12 \mathrm{E}, \quad 30^{\circ} 40 \mathrm{~N}-31^{\circ} 53 \mathrm{~N}\right), \quad$ a coastal city, located in eastern China. In Shanghai, green belt is widely used in residential areas as green landscape infrastructure. In most residential clusters, green belts ware often planted with shrubs, trees or both shrubs and trees. A representative residential cluster in Fengxian district with a greening rate of $25 \%$ were chosen for the study. The residential cluster consists of 4 residential buildings face north and south, each building had six 
floors, each floor about three meters high. The green belts ware mainly distributed in three areas: the front of the house, between the two houses and behind the house (figure 1). The experiment was taken place in November, the time when the northwest wind became the dominant wind direction, sending air pollutants from industrial zone to the experimental area.

\subsection{Parameters and meteorological data of CFD models}

Based on ZHU Lingling et al., ${ }^{[8]}$ and Guo xiaohua et al., ${ }^{[6]}$ 's research, parameters required to establish residential cluster CFD model, including grid accuracy, building size and green belt size of the simulated area, were determined and listed (table 1). PM2.5 concentration at the upwind part of the residential cluster required by the simulation experiment was measured by air quality transmitter. The measurement equipment's accuracy is $1 \mu$ $\mathrm{g} / \mathrm{m}^{3}$, and it was installed 1.5 meters above the ground. Besides, meteorological data, which could affect PM2.5 concentration in CFD models, were also measured and listed (table 2).
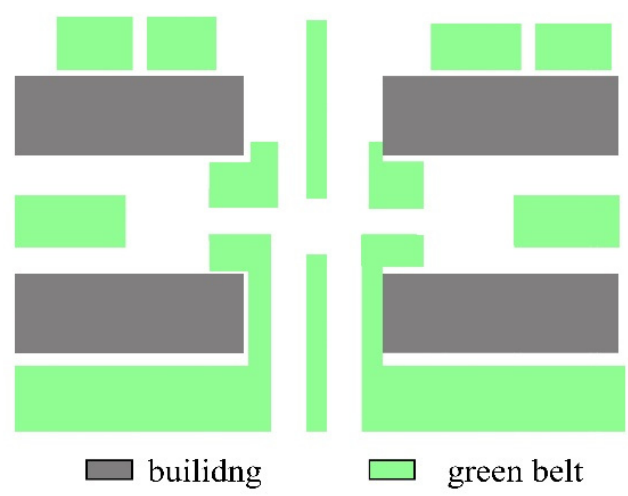

Fig1. Distribution of buildings and green belts of the experimental area

Table1. CFD model parameters

\begin{tabular}{|c|c|}
\hline Parameter & Value \\
\hline Grid accuracy & $1 \mathrm{~m} \times 1 \mathrm{~m} \times 2 \mathrm{~m}$ \\
\hline Building height & $18 \mathrm{~m}$ \\
\hline Percentage of greenbelt & $25 \%$ \\
\hline Building size & $18 \mathrm{~m} \times 64 \mathrm{~m}$ \\
\hline
\end{tabular}

Table2. Meteorological data and PM2.5 concentration

\begin{tabular}{|c|c|}
\hline Data & Value \\
\hline temperature & $11.5^{\circ} \mathrm{C}$ \\
\hline Relative humidity & $80 \%$ \\
\hline Wind speed & $2.39 \mathrm{~m} / \mathrm{s}$ \\
\hline Wind direction & $307.5^{\circ}$ \\
\hline $\begin{array}{c}\text { PM } 2.5 \\
\text { concentration }\end{array}$ & $31 \mu \mathrm{g} / \mathrm{m}^{3}$ \\
\hline
\end{tabular}

\subsection{Green belt setting}

After a survey of residential areas in Fengxian District, three widely used forms of green belts were selected. They were respectively applied to three sets of CFD models
(Table 3,4). In addition, a CFD model with no green belt was set as control group.

\subsection{CFD simulation}

The simulation experiment would calculate the concentration of PM2.5 after 24 hours' spread in residential cluster. The meteorological data and PM2.5 emission rate used in the simulation experiment were set according to the previous measurement data. Each CFD model would be simulated separately. after the simulation, data calculated by the CFD software would be used for analysis.

Table3. Three different forms of green belt

\begin{tabular}{|c|c|}
\hline Type & Description \\
\hline Shrub & $\begin{array}{c}\text { Only shrubs in the green } \\
\text { belt }\end{array}$ \\
\hline Shrub and tree & $\begin{array}{c}\text { 1-meters-wide shrub wall } \\
\text { on the outside with trees } \\
6 \text { meters apart from each } \\
\text { other on the inside }\end{array}$ \\
\hline tree & $\begin{array}{c}\text { trees } 6 \text { meters apart from } \\
\text { each other }\end{array}$ \\
\hline
\end{tabular}

Table4. Plant parameters in CFD models

\begin{tabular}{|c|c|c|}
\hline & Shrub & Tree \\
\hline Species & Photinia & Camphor tree \\
\hline Hight & $1.5 \mathrm{~m}$ & $6 \mathrm{~m}$ \\
\hline & & $0.1(0-2.4 \mathrm{~m}) ;$ \\
Leaf area profile & 2.5 & $0.6(2.4-3 \mathrm{~m}) ;$ \\
& & $1(3-5.4 \mathrm{~m}) ;$ \\
& & $0.6(5.4-6 \mathrm{~m})$ \\
\hline
\end{tabular}

\section{Results and discussion}

\subsection{Results and analysis}

The simulation results confirm that green belts do have impacts on the concentration of PM2.5 in residential cluster, and clusters with different greenbelts have different PM2.5 distribution characters (figure 2). Comparing with the control group, it could be found that fine particles in the shrub group were more likely to gather in a strip at the central area of the cluster. Besides, the shrub group had the highest overall PM2.5 concentration with the maximum value occurred in the area between green belt and the south side of the building (building d). On the contrast, the PM2.5 distribution of the tree group was much smoother. It had higher PM2.5 concentration in both inner and downwind areas for about $3.3 \mu \mathrm{g} / \mathrm{m}^{3}$ than control group. As for shrub and tree group, its PM2.5 distribution had characteristics of the above two groups. In the shrub and tree group, the highest concentration of PM2.5 had reached $22.6 \mu \mathrm{g} / \mathrm{m}^{3}$, compared with $26.4 \mu \mathrm{g} / \mathrm{m}^{3}$ in the shrub group and $21.6 \mu \mathrm{g} / \mathrm{m}^{3}$ in the tree group. In terms of overall PM2.5 concentration rank in the cluster, control group was the lowest, tree group was the third, while the group of shrub and tree came second, and the shrub group became the highest. 


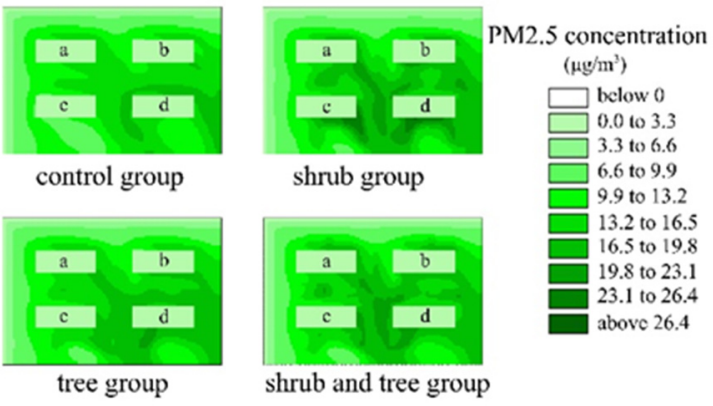

Fig2. PM2.5 concentration of the four groups.

Through the analysis of PM2.5 concentration on the north and south sides of the building, the impact of different green belts on residents' health could be seen (figure 3 and 4). For buildings in the upwind area (building $\mathrm{a}, \mathrm{b}$ and $\mathrm{c})$, all kinds of green belt in this experiment led to higher PM2.5 concentration in building's north and south side; for the building in downwind area (building $d$ ), green belt made the concentration rise in south side and down in north side.

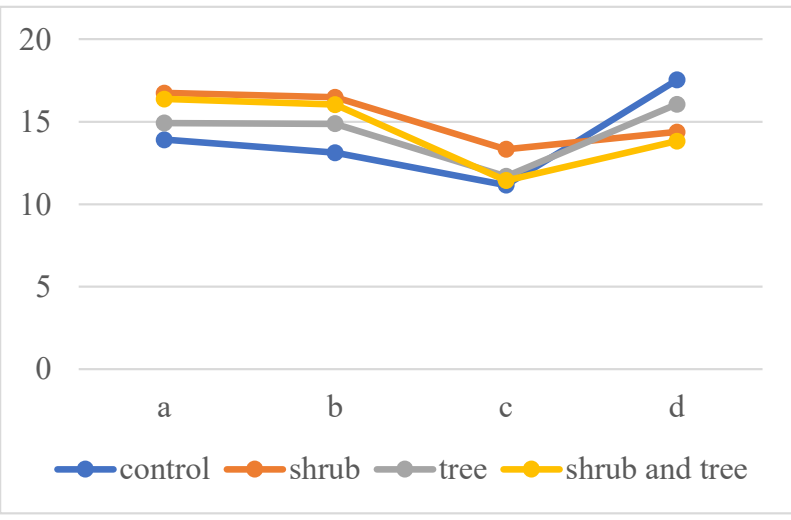

Fig3. Average PM2.5 concentration on the north side of the buildings.

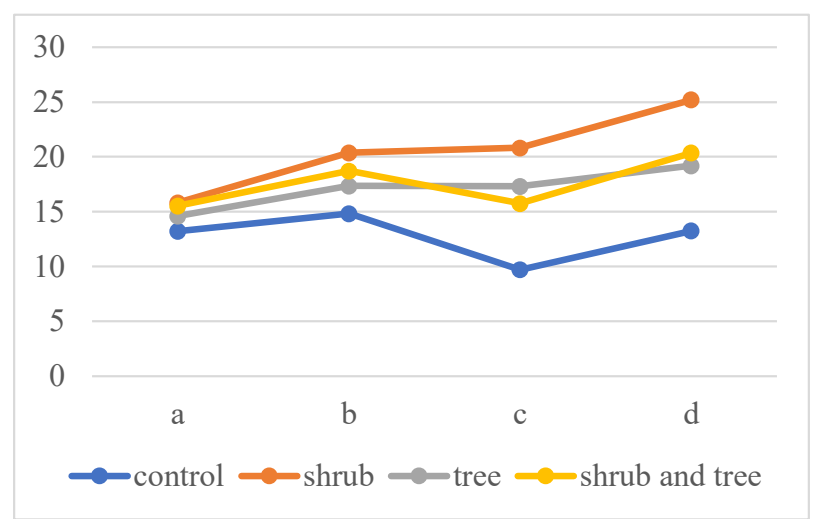

Fig4. Average PM2.5 concentration on the south side of the buildings.

\section{2 discussion}

According to Prusty et al., ${ }^{[9]}$ and Tallis et al., ${ }^{[10]}$ 's research, plants have two effects on fine particles in the air, one called the adsorption effect, and the other called retention effect. Adsorption effect allows plants to remove part of the fine particles in the air permanently, and is one of the main reasons why green spaces reduce the PM2.5 concentration in the air. As for the retention effect, the amount of particulate pollutants retained by retention effect is related to the concentration of particulate pollutants in the air. Retention effect is unstable, particles can easily return to the air due to increased wind speed or other external forces if there is no rainfall. Combine their research with Sanchez and Mccollin ${ }^{[11]}$ 's study, it can be concluded that in the absence of rainfall, a higher concentration of PM2.5 will accumulate near the green belt then affect downwind areas, Causing PM2.5 concentration rise in residential areas. This conclusion can help explain the simulation experiment results. For instance, shrub group's PM2.5 mainly gathers in the centre road of the residential cluster where there were three green belts arranged approximately in parallel. Because of the CFD model did not set rainfall factor and particles could not be deposited to the ground, a high concentration of particles had accumulated. Similar things happened in shrub and tree group. Meanwhile, the experimental results also prove that it is feasible to reduce the PM2.5 concentration in the downwind area by setting up multiple green belts in the upwind area.

As for the tree group, at the height of the canopy, the distribution of fine particles was just consistent with that of the shrub groups; at the height of the shrub layer, the fine particles were evenly distributed. Combined with previous research, the most believable explanation was that the canopy reduced air velocity and caused PM2.5 accumulation.

\section{Conclusions}

This project studied the impact of different green belts on PM2.5 concentration in residential clusters, so as to provide new methods and ideas for urban green belt landscape planning in Shanghai.

Based on the field measurement data collected in Fengxian district, three different CFD models of green belts and a control model without green belts were established. According to the simulation and analysis results, this study proves that the types of plants in the green belt and the location of green belt are decisive factors affecting the concentration of fine particulate pollutants in residential cluster. Moreover, this experiment found that green belts did not necessarily reduce PM2.5 concentrations at the cluster scale. On the contrary, under the condition of high external PM2.5 concentration and lack of rainfall, improper planned green belts could even aggravate air pollution.

This research can provide useful data and methods for the planning and renovation of green belts in residential areas in Shanghai. In addition, this experiment is based on CFD simulation. Results calculated by computers inevitably have some different from actual situation. In the future, taking more factors into consideration will make the calculation results more realistic. 


\section{References}

1. Cohen A J, Brauer M, Burnett R, et al. Estimates and 25 -year trends of the global burden of disease attributable to ambient air pollution: an analysis of data from the Global Burden of Diseases Study 2015[J]. Lancet: S0140673617305056 (2017)

2. WANG Zhi-peng, WANG Wei, SHEN Meng, et al. Impacts of green space on residents' health in urban residential areas: A study in two communities in Hefei [J]. Journal of Environmental and Occupational Medicine, 37(8): 772-776 (2020)

3. Nowak D J, Crane D E, Stevens J C. Air pollution removal by urban trees and shrubs in the United States[J]. Urban Forestry \& Urban Greening, 4(34):115-123 (2006)

4. Mcdonald A G, Bealey W J, Fowler D, et al. Quantifying the effect of urban tree planting on concentrations and depositions of PM10 in two UK conurbations[J]. Atmospheric Environment, 41(38):8455-8467 (2007)

5. Dai Fei, Chen Ming, Zhu Shengwei, Chen Hong, Fu Fan. Effects of Different Green Coverage in Block Scale on PM 10 and PM 2.5 Removal-A Case Study of the Main City of Wuhan[J]. Chinese Landscape Architecture, 34(03):105-110 (2018)

6. Guo Xiaohua, Dai Fei, Yin Lihua Simulation Study on reduction effect of PM2.5 by Road Green Belt Planning and Design Based on ENVI-MET. Landscape Architecture, 25 (12) :75-80 (2018)

7. Li xiangrong. Study on PM2.5 Pollution and Numerical Simulation of Street Canyon in Chongqing [D]. ChongQing university (2019)

8. ZHU Lingling, GU Kangkang, FANG Yunhao Study residential areas and PM 2.5 concentration based on Envi-met. Ecology and Environmental Sciences 28(8): 1613-1621 (2019)

9. Prusty BAK, Mishra PC, Azeez PA. Dust accumulation and leaf pigment content in vegetation near the national highway at Sambalpur, Orissa, India. Ecotoxicology and Environmental Safety, 60: 228-235 (2005)

10. Tallis M, Taylor G, Sinnett D, et al. Estimating the re-moval of atmospheric particulate pollution by the urban tree canopy of London, under current and future environments. Landscape and Urban Planning, 103: 129-138 (2011)

11. SANCHEZ I A, MCCOLLIN D, A comparison of microclimate and environmental modification produced by hedgerows and dehesa in the Mediterranean region: A study in the Guadarrama region, Spain [J]. Landscape and Urban Planning, 143(1): 230-237 (2015) 